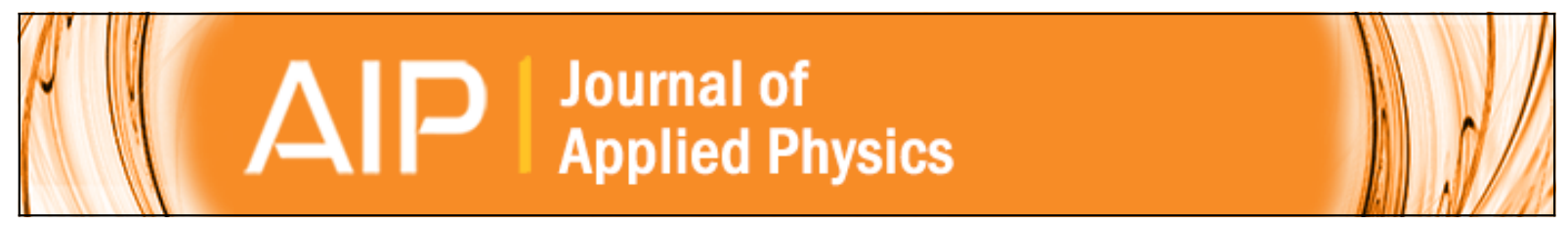

\title{
Magnetic and structural properties of ion nitrided stainless steel
}

R. L. O. Basso, V. L. Pimentel, S. Weber, G. Marcos, T. Czerwiec, I. J. R. Baumvol, and C. A. Figueroa

Citation: Journal of Applied Physics 105, 124914 (2009); doi: 10.1063/1.3153945

View online: http://dx.doi.org/10.1063/1.3153945

View Table of Contents: http://scitation.aip.org/content/aip/journal/jap/105/12?ver=pdfcov

Published by the AIP Publishing

\section{AlP Re-register for Table of Content Alerts}

\section{Create a profile. \\ Sign up today!}




\title{
Magnetic and structural properties of ion nitrided stainless steel
}

\author{
R. L. O. Basso, ${ }^{1,2}$ V. L. Pimentel, ${ }^{3}$ S. Weber, ${ }^{4}$ G. Marcos, ${ }^{5}$ T. Czerwiec, ${ }^{5}$ \\ I. J. R. Baumvol, ${ }^{1,6, a)}$ and C. A. Figueroa ${ }^{1, a)}$ \\ ${ }^{1}$ Centro de Ciências Exatas e Tecnologia, Universidade de Caxias do Sul, 95070-560 Caxias do Sul, RS, \\ Brazil \\ ${ }^{2}$ Instituto de Física "Gleb Wataghin," Unicamp, 13083-970 Campinas, SP, Brazil \\ ${ }^{3}$ Laboratório Nacional de Luz. Síncrotron, 13084-971 Campinas, SP, Brazil \\ ${ }^{4}$ Laboratoire de Physique des Matériaux, UMR CNRS 7556, Ecole des Mines, Parc de Saurupt, 54042 \\ Nancy Cedex, France \\ ${ }^{5}$ Laboratoire de Science et Génie des Surfaces, UMR CNRS 7570, France and Institut National \\ Polytechnique de Lorraine, Ecole des Mines de Nancy, Parc de Saurupt, 54042 Nancy Cedex, France \\ ${ }^{6}$ Instituto de Física, Universidade Federal do Rio Grande do Sul, Porto Alegre 91509-970, Brazil
}

(Received 9 April 2009; accepted 18 May 2009; published online 29 June 2009)

\begin{abstract}
The magnetic properties and crystalline structure of expanded austenite obtained by ion beam nitriding of AISI 316 steel are investigated. Magnetic force microscopy reveals that the nitrogen expanded austenite has two different layers, an outermost ferromagnetic layer and a paramagnetic layer beneath it. Superimposing the nitrogen concentration profile determined by secondary neutral mass spectrometry and the magnetic force microscopy image, one can see that the paramagnetic-ferromagnetic transition takes place at the inflection point of the nitrogen concentration profile at about $14 \pm 2 \mathrm{~N}$ at. \%. Conventional and glancing angle $\mathrm{x}$-ray diffraction suggests that nitrogen could occupy first tetrahedral interstitial positions (nitrogen-poor paramagnetic phase) and then, after saturation of $\mathrm{Cr}$ traps, octahedral interstitial positions (nitrogen-rich ferromagnetic phase). The ferromagnetic-paramagnetic transition is seen to be governed by $\mathrm{Cr}$ (traps)-N interactions. (C) 2009 American Institute of Physics.
\end{abstract}

[DOI: $10.1063 / 1.3153945$ ]

\section{INTRODUCTION}

Plasma surface modification of materials is commonly used to increase hardness, to improve wear and corrosion resistance, and to reduce friction. ${ }^{1-3}$ Plasma nitriding of austenitic stainless steel, in particular, attracted strong interest owing to the formation of the expanded austenite $\left(S, \gamma_{\mathrm{N}}\right.$, or $m$ phase), a nitrogen-supersaturated compound with fcc-like crystalline structure. ${ }^{4} \mathrm{~A}$ wealth of research was devoted to explain the nature of expanded austenite, so far without a satisfactory understanding of its formation and structure. ${ }^{5-11}$ According to literature, the expanded austenite is the main phase in different austenitic stainless steel surfaces after nitrogen $(\mathrm{N})$ ion implantation. ${ }^{12}$ It was recently suggested the presence of two different phases in the nitrided layer. ${ }^{12,13}$ Furthermore, low-iron metal alloys with fcc-like structure such as Inconel also presented the formation of two different expanded austenite phases. ${ }^{14}$ Magnetic force microscopy (MFM) was used to show that the outermost layer is ferromagnetic and covers up to $80 \%$ of the total nitrided layer thickness, ${ }^{15}$ whereas the inner layer was shown to be paramagnetic, similar to the bulk material (austenitic stainless steel AISI 316). In addition, it is well established that nitrogen in expanded austenite is located in interstitial sites, forming a solid solution, and in the vicinity of chromium $(\mathrm{Cr})$ atoms. ${ }^{16}$ In fact, $\mathrm{Cr}$ atoms act as traps for nitrogen due to their high chemical affinity. ${ }^{17-19}$

\footnotetext{
${ }^{a)}$ Authors to whom correspondence should be addressed. Electronic addresses: ijrbaumvol@ucs.br and cafiguer@ucs.br.
}

The fcc-like crystalline structure of the N-supersaturated compound is not isotropic. The (200) anomalous expansion in the fcc crystalline structure ${ }^{20,21}$ and the plastic deformation that takes place in nitrided austenitic stainless steel ${ }^{22}$ are strong evidences that $\mathrm{Cr}-\mathrm{N}$ interaction plays a significant role in the transition from the original austenitic phase to the final expanded austenitic phase. However, atomic-scale investigation of the occurrence of this phase transition as well as on the location of $\mathrm{N}$ (octahedral and/or tetrahedral sites) and on how $\mathrm{N}$ can produce anisotropic distortions in fcc-like structures are still needed.

This paper aims at a better understanding of the structure and properties of expanded austenite formed by ion beam nitriding of austenitic stainless steel, in particular, the magnetic properties, crystalline structure, and nitrogen transport and incorporation.

\section{EXPERIMENTAL}

Mirror polished samples of AISI 316 stainless steel (C: $<0.08$, Si: <0.5, P: 0.05, S: 0.03, Mn: 1.6, Mo: 2.1, Ni: 12.0, Cr: 17.0, Fe: balance in wt. \%) were used. Nitriding was performed in an ion implantation chamber equipped with a $30 \mathrm{~mm}$ diameter dc Kaufman ion source. ${ }^{23,24}$ Nominal ion beam energy and current density were fixed at $600 \mathrm{eV}$ and $1.2 \mathrm{~mA} \mathrm{~cm}^{-2}$, respectively. ${ }^{25,26}$ The background chamber pressure is $10^{-5} \mathrm{~Pa}\left(\mathrm{PO}_{2}<2 \times 10^{-6} \mathrm{~Pa}\right)$ and the nitrogen working pressure was fixed at $10^{-2} \mathrm{~Pa}$. The feeding gas of the Kaufman ion source is trough mass flowmeter controllers and the ion incidence perpendicular to the sample surface. 
The substrate temperature during implantation was $380 \pm 10{ }^{\circ} \mathrm{C}$. Nitriding time was varied from 5 to $120 \mathrm{~min}$. $\mathrm{X}$-ray diffraction (XRD) analyses were performed using a Siemens D500 X-ray diffractometer with Co $K \alpha$ radiation in glancing incidence angle (GIXRD) and in Bragg-Brentano (BB), $\theta-2 \theta$ geometry. The $\mathrm{N}$ concentration profiles were determined by secondary neutral mass spectrometry (SNMS). A 5-8 $\mathrm{keV} \mathrm{Ar}^{+}$beam was used to produce 250 or $500 \mu \mathrm{m}^{2}$ craters. The depth of each sputtered crater was measured with a high precision profilometer in order to calibrate the depth scale. ${ }^{27}$ Nitrogen was quantified by calibrating against a $\gamma^{\prime}-\mathrm{Fe}_{4} \mathrm{~N}$ standard. The morphology of the samples was analyzed by cross-section scanning electron microscopy (SEM), atomic force microscopy (AFM), and MFM. SEM analyses were performed in a JEOL JSM-5900LV apparatus. In order to reveal the microstructure, the samples for SEM analyses were etched for $5 \mathrm{~s}$ in a $\sim 10 \%$ marble solution, followed by rinsing in analytical alcohol to stop the etching. AFM and MFM analyses were performed using a Dimension 3000-Digital Instruments Corporation scanning-probe microscope. Unlike more conventional microscopies, this class of microscope generates images of the sample surface by raster scanning a fine-tipped probe over a region of up to $100 \mu \mathrm{m}^{2}$. A Co-Ni alloy coated tip was used for magnetic measurements.

\section{RESULTS}

Figures 1(a)-1(c) show, respectively, cross-section SEM, AFM, and MFM images of the sample nitrided for $120 \mathrm{~min}$. The surface is on the left-hand side of the images. Figure 1(a) shows a SEM image in secondary electron mode, indicating a homogenous nitrided layer. The AFM image, Fig. 1(b), on the other hand, indicates a depression at the end of the nitrided layer, visualized as a darker zone in the middle region of the image. Finally, the MFM image of Fig. 1(c) clearly reveals that the nitrided layer is divided in two well defined zones. The outermost zone is formed by domes and the inner zone is flat.

Figure 2 shows the $\mathrm{N}$ concentration profiles for different nitriding times as determined by SNMS. It is important to remark that the $\mathrm{N}$ content determined by SMNS is underestimated as compared to the one determined by XPS (not shown). The $\mathrm{N}$ profiles present two different characteristic regimes, namely, a slowly decreasing profile for the outermost layer (regime A) and a fastly decreasing one for the innermost layer (regime B). Both slopes are depicted by dashed lines, indicated by arrows, in Fig. 2 in the N profile for the sample nitrided during $120 \mathrm{~min}$.

Figure 3 shows the XRD patterns for different nitriding times in $\mathrm{BB} \theta-2 \theta$ geometry. Increasing the nitriding time leads to an increase in the diffraction peaks, assigned to the expanded austenite $\left(\gamma_{\mathrm{N}}\right)$ with respect to the peak assigned to the original austenite $(\gamma)$. One notices also from Fig. 3 that the intensity of plane $\gamma_{\mathrm{N}^{-}}(200)$ increases with respect to that of $\gamma_{\mathrm{N}^{-}}$(111) for increasing nitriding times. In fact, for the 5 min nitriding time, only the peak associated with plane $\gamma_{\mathrm{N}^{-}}(111)$ is clearly visible in the diffractogram.

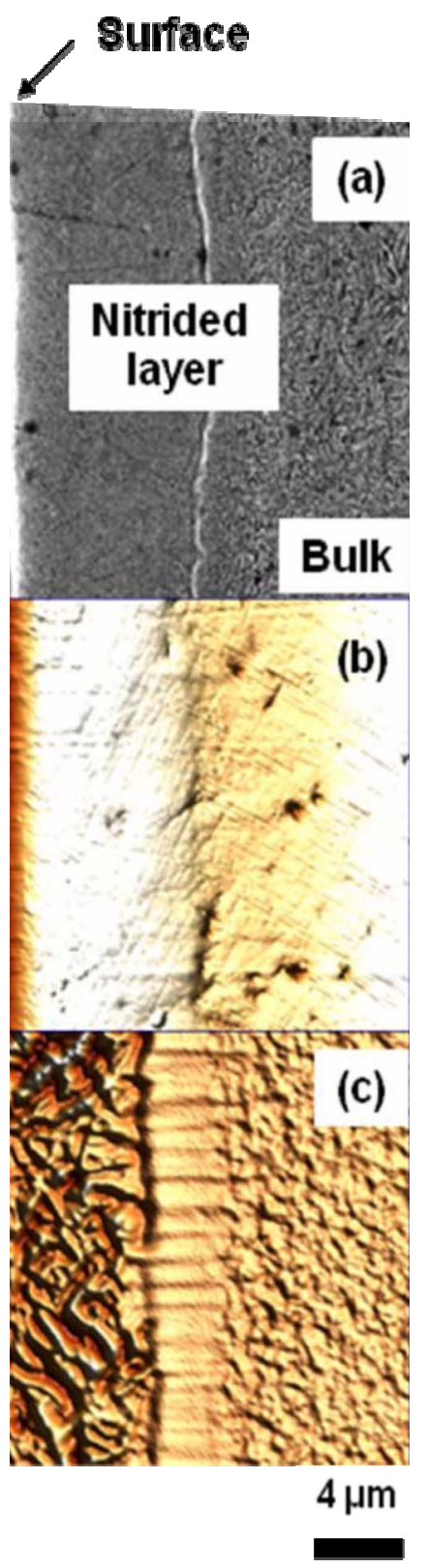

FIG. 1. (Color online) Cross-section images of the nitrided layer showing the morphology obtained by (a) SEM, (b) AFM, and (c) MFM.

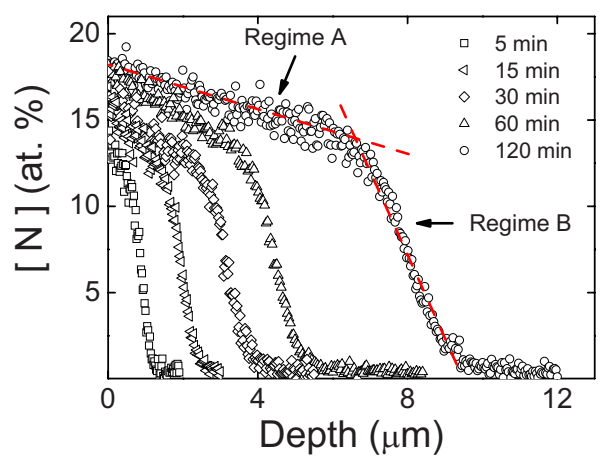

FIG. 2. (Color online) Nitrogen concentration as a function of depth for different nitriding times as determined by SNMS. Two dashed lines were drawn in the experimental curve for the sample nitrided for $120 \mathrm{~min}$ to indicate two different $\mathrm{N}$ transport regimes. 


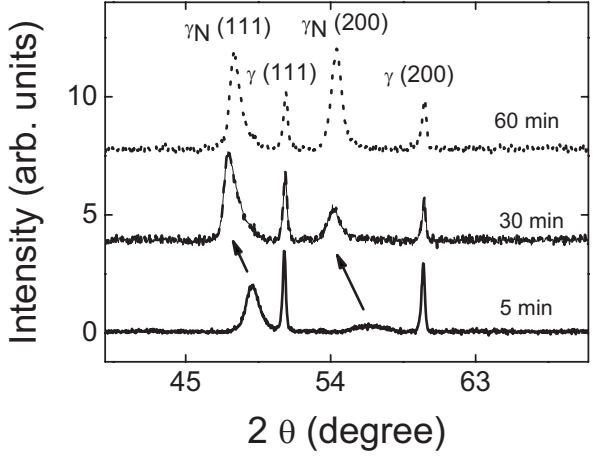

FIG. 3. X-ray diffractograms in BB $\theta-2 \theta$ geometry for samples nitrided during different nitriding times.

\section{DISCUSSION}

\section{A. Morphology of expanded austenite}

The three dimensional MFM image of Fig. 4 shows the magnetic domains of a ferromagnetic phase in the outermost part of the nitrided layer. The innermost part of the nitrided layer shows a paramagnetic phase, represented by a flat, nonmagnetic signal. Several authors observed the presence of ferromagnetism in nitrided ASS 316 steel. ${ }^{28-30}$ Interesting applications of magnetic properties in nitrided austenitic stainless steel have been demonstrated. ${ }^{31}$ Thus, the outermost layer is a nitrogen-rich ferromagnetic phase and the innermost layer is a nitrogen-poor paramagnetic phase. For clearness, Fig. 5 shows the superposition of the nitrogen profile and the MFM image of the nitrided layer for the same sample nitrided for $120 \mathrm{~min}$, which allows establishing the correlation between the type of expanded austenite phase and its nitrogen content. From Fig. 5, one can see that the ferromagnetic-paramagnetic transition takes place around the inflection in the nitrogen profile. The $\mathrm{N}$ concentration determined here around the inflection point was approximately $14 \pm 2$ at. \%, whereas previous nuclear reaction analysis

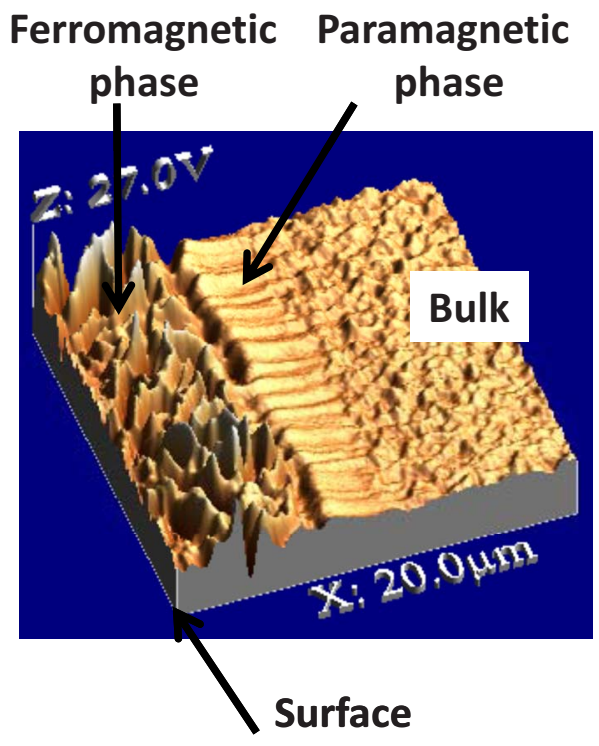

FIG. 4. (Color online) Three dimensional MFM image for the sample nitrided for $120 \mathrm{~min}$. The peaks in the near-surface layer represent the magnetic domains of the ferromagnetic phase.

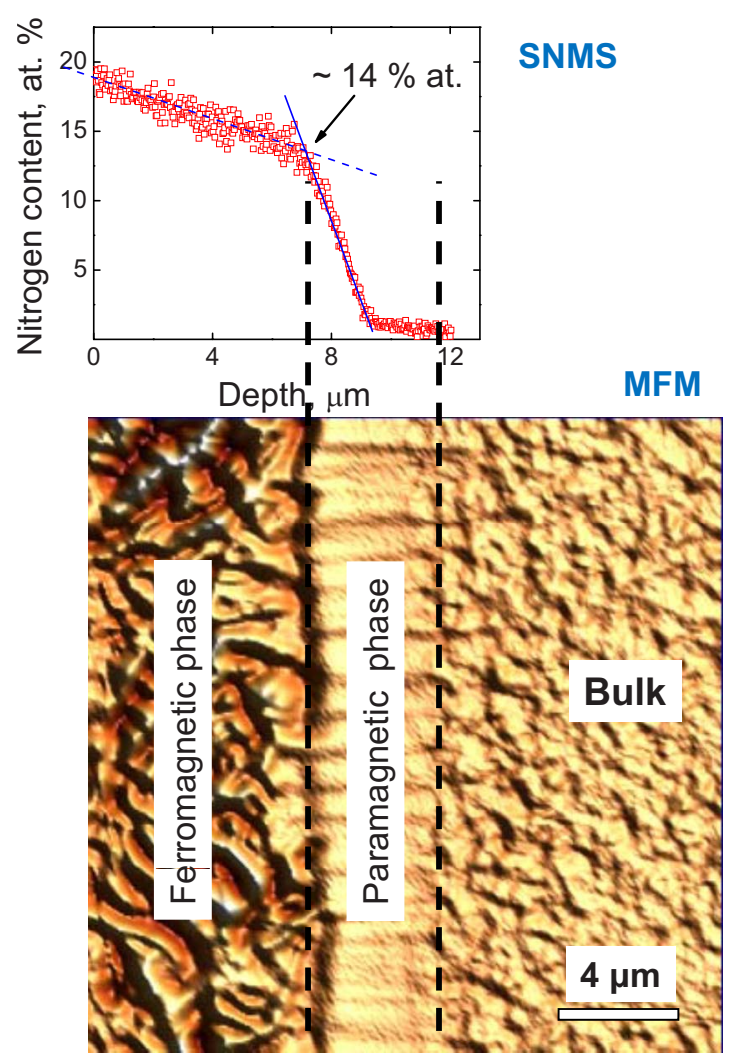

FIG. 5. (Color online) (Top) N concentration profile for the sample nitrided during $120 \mathrm{~min}$ as determined by SNMS. (Bottom) MFM image from the same sample, indicating two different magnetic phases in the nitrided layer (expanded austenite) at the left hand side. The dashed line is a guide to the eyes to connect the magnetic phase transition and the inflexion in the nitrogen content at 14 at. $\%$.

work obtained about $17 \mathrm{~N} \% .{ }^{18}$ One notices here that these inflections occur for $\mathrm{N}$ concentrations comparable to the $\mathrm{Cr}$ content of the steel, around $17 \mathrm{Cr} \%$.

\section{B. Magnetic properties of expanded austenite}

ASS 316 is a paramagnetic alloy. Upon nitriding, the alloy remains paramagnetic up to a nitrogen content of approximately 14 at. \%. For higher $\mathrm{N}$ concentrations, a ferromagnetic phase is formed. One can discuss the nature of this transition from para- to ferromagnetic phase. The magnetic properties of transition metals are due to the spin interactions of valence band electrons. In our case, electrons from $3 d$ orbitals of $\mathrm{Fe}, \mathrm{Ni}$, and $\mathrm{Cr}$ control the magnetic properties of ASS 316. Furthermore, the paramagnetic-ferromagnetic transition dependence on $\mathrm{N}$ incorporation occurs by two different mechanisms, (i) the rearrangement of $3 d$ electrons after changing the $\mathrm{Fe}-\mathrm{Cr}-\mathrm{Ni}$ atomic distances and/or (ii) the formation of metallic nitrides $(\mathrm{MeN}, \mathrm{Me}=\mathrm{Fe}, \mathrm{Cr}, \mathrm{Ni})$. Concerning the first mechanism, it was shown ${ }^{32}$ that a local ferromagnetism in ASS 316 is generated by nanoindentation, which leads to a phase transition to ferromagnetic bct martensite. As for the second mechanism, all types of iron nitrides $\left(\mathrm{Fe}_{16} \mathrm{~N}_{2}, \mathrm{Fe}_{4} \mathrm{~N}, \mathrm{Fe}_{2-3} \mathrm{~N}\right)$ are ferromagnetic. ${ }^{33-37}$ Thus, both factors are apparently acting in the system investigated in the present work. However, since the nitrogen concentration at the inflection point compares well with the chromium concentration, one can think of a first stage where nitrogen 


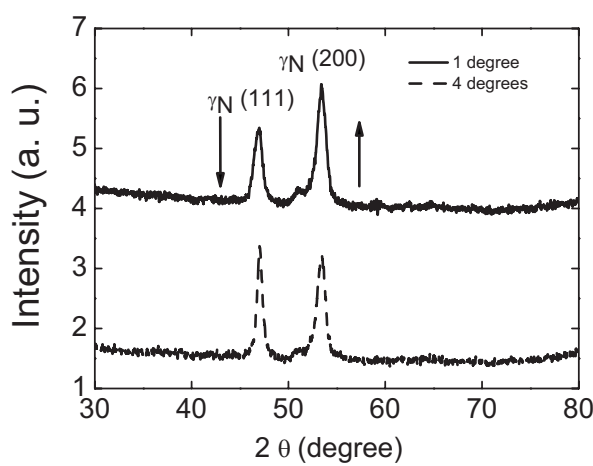

FIG. 6. X-ray diffractograms for the sample nitrided during $120 \mathrm{~min}$ in glancing incidences of $1^{\circ}$ and $4^{\circ}$. The arrows indicate the changes in the intensity of planes (200) and (111), respectively.

bonds rapidly and preferentially to $\mathrm{Cr}$ (see regime $\mathrm{B}$ in Fig. 2), owing to the higher heat of formation of $\mathrm{CrN}$ than $\mathrm{FeN}_{x}$ and $\mathrm{NiN}_{x}$ (chemical trap). ${ }^{38}$ Consequently, nitrogen removes $\mathrm{Cr} 3 d$ electrons from the metallic alloy valence band. Since pure $\mathrm{Cr}$ is a paramagnetic metal, whereas pure iron and nickel are ferromagnetic, ${ }^{39}$ a metal alloy containing iron and nickel should yield a ferromagnetic phase. ${ }^{40,41}$ In addition, fcc- $\left(\mathrm{Fe}_{1-x} \mathrm{Ni}_{x}\right)_{4} \mathrm{~N}$ is also ferromagnetic and the higher the iron content the higher the magnetic moment of this nitrided metal alloy. ${ }^{42}$ Consequently, a rule of mixture for the magnetic moments might be used in this case because nickel is less ferromagnetic than iron. ${ }^{39}$ We argue that the most important effect governing the ferromagnetism of the expanded austenite above $14 \mathrm{~N}$ at. \% is the $\mathrm{N}-\mathrm{Cr}$ interaction, which removes the chromium $3 d$ electrons from the metal alloy valence band.

\section{Crystalline structure of expanded austenite}

The crystalline structure of nitrogen expanded austenite is not fully described yet. It is generally accepted that expanded austenite is a distorted fcc-like phase with anisotropic expansion due to internal stress. ${ }^{43}$ However, the question on where nitrogen is located still remains unanswered. Further XRD diffraction analyses were undertaken aiming at clarifying this point. Figure 6 shows x-ray diffractograms at glancing incidences (GIXRD) of $1^{\circ}$ and $4^{\circ}$, for the sample nitrided during $120 \mathrm{~min}$. These incidence angles provide information on layers 0.5 and $2 \mu \mathrm{m}$ below the surface, respectively. Thus, from Fig. 6 one notices that the intensity of the diffraction peak associated with the $\gamma_{\mathrm{N}^{-}}(200)$ plane is higher near the surface. In addition, as shown in Fig. 3, the intensity associated with the plane (200) increases with the increase in nitriding time, or in other words with the increase in $\mathrm{N}$ concentration. Hence, either in the analysis of the same sample by GIXRD or in the analysis of different samples by conventional BB geometry, the higher the nitrogen content the higher the intensity of plane (200).

Simulations of $\mathrm{x}$-ray diffractograms with the Power Cell 2.4 (Ref. 44) code shows that nitrogen in interstitial sites modulates the intensity of peaks, for example, in the (111) versus (200) planes. ${ }^{45}$ As more nitrogen is located in tetrahedral (or octahedral) interstitial sites, the intensity of constructive interference associated with plane (111) [or (200)] in-
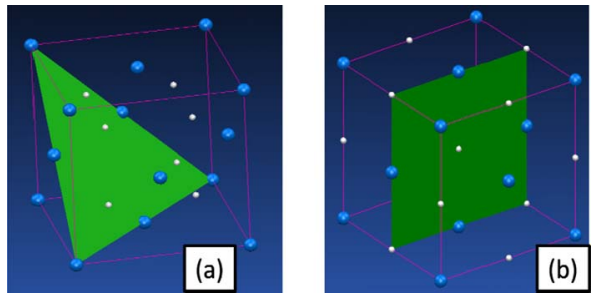

FIG. 7. (Color online) Ideal fcc crystalline structures with plane (111) crossing nitrogen in tetrahedral (a) and plane (200) crossing nitrogen in octahedral (b) interstitial sites.

creases. Figures 7(a) and 7(b) show two ideal fcc crystalline structures with plane (111) crossing $\mathrm{N}$ in tetrahedral and plane (200) crossing $\mathrm{N}$ in octahedral interstitial sites (white dots), respectively. Considering these simulations and the results of Fig. 6, one can conclude that, in near-surface expanded austenite, most of the nitrogen should be located at octahedral sites. The same is observed in Fig. 3, where the relative intensity of plane (200) increases with the increase in nitriding time. Figure 8 shows the diffraction intensity ratio for planes $(111) /(200)$ as a function of nitriding time, where the intensity ratio is seen to decrease as the nitriding time increases. In other words, more nitrogen should incorporate in octahedral positions at longer nitriding times. This scenario suggests that at lower nitriding times, when only the intensity associated with the (111) plane is significative, most of the nitrogen should occupy tetrahedral positions due to the minimization of $\mathrm{Cr}-\mathrm{N}$ distances, forming nanoclusters of $\mathrm{CrN}$ up to saturation of all $\mathrm{Cr}$ traps (nitrogen-poor paramagnetic phase). ${ }^{16}$ Then, by increasing the $\mathrm{N}$ concentration, it should be incorporated in octahedral positions (nitrogen-rich ferromagnetic phase). In fact, one single analytical technique is not sufficient to establish the exact position of nitrogen in the expanded austenite. Therefore, new characterizations by conversion electron Mossbauer scattering and high resolution transmission electron microscopy are being performed and will make the subject of a forthcoming publication.

\section{CONCLUSIONS}

Magnetic and structural properties of expanded austenite produced by ion beam nitriding are reported. Two different magnetic layers were observed, the outermost one being ferromagnetic and the innermost one paramagnetic. The nitro-

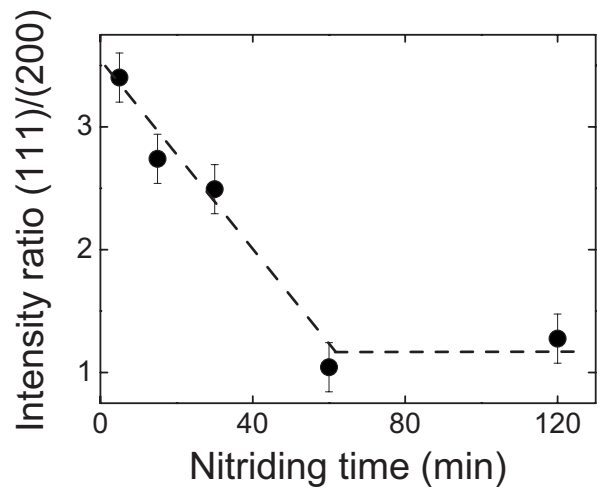

FIG. 8. $I_{111} / I_{200}$ intensity ratio as a function of nitriding time. 
gen concentration profiles present two well-distinguished regimes. The inflection point between them is situated approximately at the same depth as that of the transition from the ferromagnetic to the paramagnetic phase layer, around $14 \pm 2 \mathrm{~N}$ at. \%. The transition from the ferromagnetic to the paramagnetic phase layer is attributed to a mechanism governed by the strong chromium-nitrogen interaction. XRD experimental results and simulations suggest that at the beginning of the expanded austenite formation, nitrogen is mostly located in tetrahedral interstitial positions (nitrogen-poor paramagnetic phase). The increase in nitrogen concentration leads to saturation of chromium traps, which causes nitrogen to be incorporated in octahedral interstitial positions (nitrogen-rich ferromagnetic phase). The $\mathrm{Cr}-\mathrm{N}$ interaction removes the $\mathrm{Cr} 3 d$ electrons from the metal alloy valence band promoting ferromagnetism.

\section{ACKNOWLEDGMENTS}

This work was partially sponsored by FAPESP, Project Nos. 05/53926-1 and 04-01977. SEM, AFM, and MFM analyses were performed at LNLS (Campinas, SP, Brazil). The authors are indebted to F. Alvarez for helping with the measurements at IFGW-UNICMP (Campinas, SP, Brazil). I.J.R.B. is a CNPq fellow.

${ }^{1}$ K. Navaneetha Pandiyaraj, V. Selvarajan, R. R. Deshmukh, and C. Gao, Appl. Surf. Sci. 255, 3965 (2009).

${ }^{2}$ J. Jun, M. Dhayal, B. H. Kim, and H. G. Woo, J. NanoSci. Nanotechnol. 8, 5537 (2008).

${ }^{3}$ B. Rayner, X. Y. Li, and H. Dong, Surf. Eng. 22, 103 (2006).

${ }^{4}$ Z. L. Zhang and T. Bell, Surf. Eng. 1, 131 (1985)

${ }^{5}$ S. P. Hannula, P. Nenomen, and J. P. Hirvonen, Thin Solid Films 181, 343 (1989).

${ }^{6}$ A. Saker, Ch. Leroy, H. Michel, and C. Frantz, Mater. Sci. Eng., A 140, 702 (1991).

${ }^{7}$ G. A. Collins, R. Hutchings, K. T. Short, J. Tendys, X. Li, and M. Samandi, Surf. Coat. Technol. 74-75, 417 (1995).

${ }^{8}$ Y. Sun, X. Li, and T. Bell, J. Mater. Sci. 34, 4793 (1999).

${ }^{9}$ R. Wei, B. Shogrin, P. J. Wilbur, O. Ozturk, D. L. Williamson, I. Ivanov, and E. Metin, Trans. ASME, J. Tribol. 116, 870 (1994).

${ }^{10}$ E. Menthe, K. T. Rie, J. W. Schultze, and S. Simson, Surf. Coat. Technol. 74-75, 412 (1995)

${ }^{11}$ S. Parascandola, R. Gunzel, R. Grotzchel, E. Richter, and W. Möller, Nucl. Instrum. Methods Phys. Res. B 136-138, 1281 (1998).

${ }^{12}$ D. L. Williamson, J. A. Davis, and P. J. Wilbur, Surf. Coat. Technol. 103-104, 178 (1998)

${ }^{13}$ T. Czerwiec, N. Renevier, and H. Michel, Surf. Coat. Technol. 131, 267 (2000).
${ }^{14}$ T. Czerwiec, H. He, A. Saker, L. Tran Huu, C. Dong, C. Frantz, and H. Michel, Surf. Coat. Technol. 174-175, 131 (2003).

${ }^{15}$ M. P. Fewell, D. R. G. Mitchell, J. M. Priest, K. T. Short, and G. A. Collins, Surf. Coat. Technol. 131, 300 (2000).

${ }^{16}$ P. Kizler, G. Frommeyer, and R. Rosenkranz, Z. Metallkd. 85, 705 (1994).

${ }^{17}$ S. Parascandola, W. Möller, and D. L. Williamson, Appl. Phys. Lett. 76, 2194 (2000)

${ }^{18}$ G. Abrasonis, J. P. Rivière, C. Templier, L. Pranevicius, and N. P. Barradas, J. Appl. Phys. 97, 124906 (2005).

${ }^{19}$ C. A. Figueroa and F. Alvarez, Surf. Coat. Technol. 200, 498 (2005).

${ }^{20}$ S. Mändl and B. Rauschenbach, J. Appl. Phys. 88, 3323 (2000).

${ }^{21}$ G. Abrasonis, J. P. Rivière, C. Templier, A. Declémy, L. Pranecius, and X. Milhet, J. Appl. Phys. 97, 083531 (2005).

${ }^{22}$ S. Grigull and S. Parascandola, J. Appl. Phys. 88, 6925 (2000).

${ }^{23}$ H. R. Kaufman, J. Vac. Sci. Technol. 15, 272 (1978).

${ }^{24}$ P. Hammer, N. M. Victoria, and F. Alvarez, J. Vac. Sci. Technol. A 16, 2941 (1998).

${ }^{25} \mathrm{H}$. Ch. Paulini and U. Littmark, Nucl. Instrum. Methods Phys. Res. B 58, 260 (1991).

${ }^{26}$ D. Van Vechten, G. K. Hubler, and E. P. Donovan, Vacuum 36, 841 (1986).

${ }^{27}$ M. J. Baldwin, S. Kumar, J. M. Priest, M. P. Fewell, K. E. Prince, and K. T. Short, Thin Solid Films 108, 345 (1999).

${ }^{28}$ M. Olzon-Dionysio, S. D. de Souza, R. L. O. Basso, and S. de Souza, Surf. Coat. Technol. 202, 3607 (2008).

${ }^{29}$ R. Wei, Surf. Coat. Technol. 83, 218 (1996).

${ }^{30}$ O. Öztürk and D. L. Williamson, Appl. Phys. Lett. 77, 3839 (1995).

${ }^{31}$ E. Menéndez, A. Martinavicius, M. O. Liedke, G. Abrasonis, J. Fassbender, J. Sommerlatte, K. Nielsch, S. Suriñach, M. D. Baró, J. Nogués, and J. Sort, Acta Mater. 56, 4570 (2008).

${ }^{32}$ J. Sort, A. Concustell, E. Menéndez, S. Suriñach, M. D. Baró, J. Farran, and J. Nogués, Appl. Phys. Lett. 89, 032509 (2006).

${ }^{33}$ M. Takahashi, H. Shoji, H. Takahashi, H. Nashi, T. Wakiyama, M. Doi, and M. Matsui, J. Appl. Phys. 76, 6642 (1994)

${ }^{34}$ Y. Kong, J. Pelzl, and F. Li, J. Magn. Magn. Mater. 195, 483 (1999).

${ }^{35}$ S. Matar, B. Siberchicot, M. Pénicaud, and G. Demazeau, J. Phys. I 2, 1819 (1992).

${ }^{36}$ G. M. Chen, N. K. Jaggl, J. B. Butt, E. B. Yeh, and L. H. Schwartz, J. Phys. Chem. 87, 5326 (1983).

${ }^{37}$ K. H. Eickel and W. Pitsch, Phys. Status Solidi 39, 121 (1970).

${ }^{38}$ M. Kopcewicz, J. Jagielsky, G. Gawlik, and A. Grabias, J. Appl. Phys. 78, 1312 (1995).

${ }^{39}$ K. Umino, H. Nakajima, and K. Shiiki, J Magn. Magn. Mater. 153, 323 (1996).

${ }^{40}$ M. Schröter, H. Ebert, H. Akai, P. Entel, E. Hoffmann, and G. G. Reddy, Phys. Rev. B 52, 188 (1995).

${ }^{41}$ A. V. Ruban, S. Khmelevskyi, P. Mohn, and B. Johansson, Phys. Rev. B 76, 014420 (2007).

${ }^{42}$ X. G. Diao, A. Y. Takeuchi, F. Garcia, R. B. Scorzelli, and H. R. Rechenberg, J. Appl. Phys. 85, 4485 (1999).

${ }^{43}$ T. Czerwiec, H. He, G. Marcos, T. Thiriet, S. Weber, and H. Michel (unpublished).

${ }^{44}$ W. Kraus and G. Nolze, POWDERCELL for windows, version 2.4, 2000.

${ }^{45}$ C. Kittel, Introduction to Solid State Physics, 7th ed. (Wiley, New York, 1996). 